\title{
Advances in Barrett's Esophagus and Esophageal Adenocarcinoma
}

\author{
NICHOLAS J. SHAHEEN \\ Center for Esophageal Diseases and Swallowing, Department of Medicine, University of North Carolina Schools of Medicine and Public \\ Health, Chapel Hill, North Carolina
}

Despite advances in diagnosis and therapy, esophageal adenocarcinoma remains an aggressive and usually lethal tumor. This review focuses on the epidemiology of esophageal adenocarcinoma and its presumed precursor lesion, Barrett's esophagus; the pathogenesis of the cancer; advances in treatment of adenocarcinoma and Barrett's esophagus; and strategies for cancer prevention. Emphasis is placed on recent literature. Although the absolute number of cases of adenocarcinoma in the United States is still small, the incidence of this cancer has increased dramatically in the last 40 years, and adenocarcinoma is now the predominant form of esophageal cancer in this country. Recent evidence suggests that Barrett's esophagus is more prevalent in asymptomatic individuals than previously appreciated. The pathogenesis of Barrett's esophagus is poorly understood. Given that some subjects will have repeated bouts of severe erosive esophagitis and never develop Barrett's esophagus, host factors must play an important role. The utility of neoadjuvant radiation and chemotherapy in those with adenocarcinoma, although they are widely practiced, is not of clear benefit, and some authorities recommend against it. Ablative therapies, as well as endoscopic mucosal resection, hold promise for those with superficial cancer or high-grade dysplasia. Most series using these modalities feature relatively short follow-up, and longer-term data will be necessary to better describe the effects of these therapies. The value of chemoprevention in subjects with dysplastic Barrett's esophagus by use of cyclooxygenase 2 inhibitors, nonsteroidal anti-inflammatory drugs, or proton pump inhibitors is unknown. Similarly, although endoscopic screening is widely practiced, its value in patients with chronic gastroesophageal reflux disease symptoms is of unproven value, and recommending bodies are divided as to its practice.

$\mathrm{B}$ ecause of its rapidly increasing incidence over the last 40 years, esophageal adenocarcinoma has gone from a somewhat esoteric disease entity to the predominant form of esophageal cancer in the United States. Although still a rare cause of cancer death internationally, esophageal adenocarcinoma has become a significant health concern in Western countries. Given the poor prognosis associated with the disease, a better understanding of the pathogenesis of the disease and the factors associated with increased risk is essential. Also, strategies for prevention of esophageal adenocarcinoma are hotly contested.

The following review will focus on new developments in the field of Barrett's esophagus (BE) and esophageal adenocarcinoma. Given the myriad aspects of these disease states, an exhaustive review of all that is known about them is beyond the scope of this article. Therefore, this work will concentrate on the epidemiology of the disease states, the pathogenesis of the cancer, advances in treatment, and strategies for cancer prevention. Special emphasis will be placed on recent data, with effort to place these data in the context of our knowledge of BE and esophageal adenocarcinoma.

\section{Epidemiology of Barrett's Esophagus and Esophageal Adenocarcinoma}

The incidence of esophageal adenocarcinoma in the United States has increased approximately 300\%$500 \%$ in the last 40 years. ${ }^{1-3}$ Although previous misclassification of some esophageal adenocarcinomas as gastric cardia tumors may be in part responsible for the noted increase, it does not likely explain the entire increase. If misclassification were to explain all of the increase, a concomitant decrease in the number of gastric cardia tumors might be expected over the same time period. The opposite is true; the incidence of gastric cardia tumors has not decreased and may have actually increased over this period. ${ }^{4,5}$

Less clear is the trend in the incidence of BE. Because BE is thought to be the precursor lesion to most or all cases of adenocarcinoma of the esophagus, increases in cancer might

\footnotetext{
Abbreviations used in this paper: $\mathrm{BE}$, Barrett's esophagus; EMR, endoscopic mucosal resection; GERD, gastroesophageal reflux disease; HGD, high-grade dysplasia; PDT, photodynamic therapy.

(C) 2005 by the American Gastroenterological Association 0016-5085/05/ $\$ 30.00$ doi:10.1053/j.gastro.2005.03.032
} 
be expected to be preceded by increases in the incidence of BE. Longitudinal single-center studies do show an increase in diagnosis of $\mathrm{BE}$ over the past several decades. ${ }^{6,7}$ However, this increasing trend mirrors the increasing use of upper endoscopy. It may, therefore, mean that the increased incidence of $\mathrm{BE}$ described in these studies is due to increased opportunity for detection, as well as the increasing appreciation of $\mathrm{BE}$ as a risk factor for cancer, as opposed to a true increase in prevalence.

The increasing trend in esophageal adenocarcinoma closely resembles the epidemic increase in obesity in the US population. ${ }^{8,9}$ Additionally, obesity has been strongly associated as a risk factor for esophageal adenocarcinoma, even after controlling for the severity of reflux symptoms. ${ }^{10,11}$ These 2 facts have led authorities to suggest a causal relationship between trends of increasing obesity and resultant esophageal adenocarcinoma in the US population. ${ }^{12-14} \mathrm{Al}-$ though such a relationship is certainly plausible, no causal chain has been definitely proven, and changes in other environmental exposures over the last 50 years may account for all or part of the observed increase.

One recent important contribution to this field has been the demonstration of the prevalence of $\mathrm{BE}$ in asymptomatic populations. BE has long been recognized as a possible complication of chronic reflux disease. However, $40 \%$ or more of esophageal adenocarcinoma is found in subjects without previous symptoms of reflux ${ }^{15-17}$-an observation that is inconsistent with the theory that $\mathrm{BE}$ arises from gastroesophageal reflux disease (GERD) and is the predisposing lesion to adenocarcinoma. This apparent contradiction may be at least partially explained by recent prevalence data of $\mathrm{BE}$ in asymptomatic populations. Gerson et al ${ }^{18}$ performed upper endoscopy on 110 subjects with no or negligible GERD symptoms who were presenting for colorectal cancer screening. The surprising and somewhat unsettling finding in this primarily Veterans Administration Medical Center cohort was that almost $25 \%$ of those with no GERD symptoms harbored $\mathrm{BE}$, and $8 \%$ of the subjects had long-segment disease $(>3 \mathrm{~cm})$. Other groups $^{19,20}$ have found that lesser, but still substantial, proportions of asymptomatic individuals have $\mathrm{BE}$ (Table 1). Currently unknown is whether these asymptomatic individuals with $\mathrm{BE}$ have the same increased risk of cancer that has been shown in previous, symptomatic cohorts that have been followed up longitudinally.

Also unknown is the exact risk of cancer in subjects with BE. Initial reports pegged this risk at $1 \%$ or more per year. More recent reports and a meta-analysis have suggested this risk to be approximately half that amount. ${ }^{21-24}$ Of course, these analyses provide rough estimates based on accumulated data from cohorts for multiple years. It is quite possible (perhaps even likely) that cancer risk is unevenly spread in any given subject's "Barrett's lifetime." For instance, it may be that the initial period immediately after the development of the $\mathrm{BE}$ is a critical time in which a subgroup of subjects experience rapid progression through degrees of dysplasia to cancer. Conversely, perhaps nondysplastic BE of 10 years' duration is at very little, if any, risk of progression. Because the exact time of development of $\mathrm{BE}$ in subjects diagnosed with the condition is unknown, we have no data as to cancer risk as a function of the duration of preceding $\mathrm{BE}$.

\section{Pathogenesis of Barrett's Esophagus and Cancer}

$\mathrm{BE}$ is thought to be a sequela of chronic reflux disease. Subjects with chronic reflux disease seem to harbor $\mathrm{BE} 5 \%-15 \%$ of the time. ${ }^{25-27}$ However, it is unclear why some subjects develop severe recurrent erosive esophagitis and never develop $\mathrm{BE}$, whereas others with relatively few symptoms and little or no inflammatory disease on upper endoscopy develop long segments of severely dysplastic disease. It has been suggested that a genetic predisposition to the development of $\mathrm{BE}$ might be a necessary prerequisite to the disease. However, to date, a "Barrett's gene" (or genes) has remained elusive. Several groups have attempted to study the heritability of $\mathrm{BE}$ as presumptive evidence of a genetic contribution to the disease. Family cohort studies have shown that BE occurs in family groups more frequently than would be expected by chance. ${ }^{28}$ However, if there is a Barrett's gene, the penetrance of the phenotype must be low, because most first-degree relatives of those with BE do not have BE themselves. ${ }^{29}$

Table 1. Prevalence of BE in Asymptomatic Cohorts

\begin{tabular}{|c|c|c|c|c|c|}
\hline Study & Year & Patient population & $\mathrm{n}$ & Prevalence of BE & $\begin{array}{c}\text { Prevalence of } \\
\text { long-segment } B E\end{array}$ \\
\hline Gerson et al18 & 2002 & Veterans Administration medical center & 110 & $25 \%$ & $7 \%$ \\
\hline Rex et al19 & 2003 & University hospital & 556 & $5.6 \%$ & $0.36 \%$ \\
\hline DeVault et al 20 & 2004 & Academic practice & 138 & 12.3 & NR \\
\hline
\end{tabular}

NR, not reported. 
Exactly where the progenitor cells leading to $\mathrm{BE}$ arise is a matter of debate. Studies using cell markers suggested that $\mathrm{BE}$ arose from pluripotent cells found in the esophagus, which, in the presence of an acidic milieu, developed into columnar epithelium. ${ }^{30,31}$ Recent work from Sarosi et al, ${ }^{32}$ however, support an alternative explanation. Using a rodent model of $\mathrm{BE}$, this group was able to show that the progenitor cells for $\mathrm{BE}$ arose in the animal's bone marrow. The mechanism by which these cells differentiate and the factors leading to the propagation of columnar instead of squamous mucosa are still largely unknown.

$\mathrm{BE}$ is thought to progress through stages of dysplasia to cancer, and, indeed, one of the strongest known predictors of cancer risk in the setting of $\mathrm{BE}$ is the degree of dysplasia. Subjects with nondysplastic BE and low-grade dysplasia have low rates of progression, whereas those with high-grade dysplasia (HGD) may experience disease progression at rates higher than $10 \%$ per year. ${ }^{33,34}$ Additionally, surgical series show concurrent undetected cancer in the resection specimen in $50 \%$ or more of patients with HGD. ${ }^{35-37}$ It has been more recently appreciated, however, that the progression through grades of dysplasia is neither orderly nor inexorable. Indeed, subjects may jump from nondysplastic BE straight to HGD or cancer without an intervening detectable low-grade dysplasia phase. ${ }^{38}$ Alternatively, subjects with HGD may undergo apparent regression of the disease and spend months or even years with no detectable dysplasia whatsoever. Data on disease progression in BE are compromised by our random-sampling endoscopic biopsy techniques. Almost all the data available on progression rates in $\mathrm{BE}$ are from studies using a random biopsy method. Even groups that use jumbo forceps and 1-cm, 4-quadrant biopsies leave the vast majority of the mucosa unsampled. It is difficult to know what percentage of apparent disease regression is real and what is due to random sampling error missing small or mosaic areas of more advanced dysplasia. Although more sophisticated methods of sampling BE by using vital stains or magnification of mucosal crypt patterns have been described, ${ }^{39-42}$ these methods have not been broadly adopted because of cost, increased time requirements, and lack of sufficient evidence of the effects of the methods on important outcomes.

\section{Advances in Treatment}

\section{Neoadjuvant and Surgical Therapy for Cancer}

The prognosis for esophageal adenocarcinoma remains dismal, with a 5-year survival for all comers of approximately $20 \% .{ }^{43-45}$ This poor result is due in part to the advanced stage of the cancer when it is usually diagnosed. More than $50 \%$ of those with this cancer present with stage III or IV disease. ${ }^{45,46}$ However, some recent strides have been made in elucidating the best care for those with adenocarcinoma.

After initial enthusiasm for neoadjuvant chemotherapy as an adjunct to surgery, a well-performed randomized controlled trial showed that neoadjuvant chemotherapy before resection does not improve survival. ${ }^{47}$ More promising have been the results of studies combining neoadjuvant chemotherapy with radiation therapy. Unblinded studies of neoadjuvant chemoradiation showed that approximately $25 \%$ of those undergoing therapy achieved a complete response and that those undergoing therapy had improved survival compared with historical controls. ${ }^{48-50}$ Given these data, prospective randomized studies have been conducted comparing multimodality therapy with surgery alone. These trials have given somewhat conflicting data. Walsh et $\mathrm{al}^{51}$ randomized 113 patients with adenocarcinoma to undergo either surgery alone or neoadjuvant chemotherapy and radiation with surgery afterward. The chemotherapy regimen was 5-fluorouracil and cisplatin based, and $40 \mathrm{~Gy}$ of radiation was delivered. These investigators found a significant downstaging of tumors in the multimodality group; fewer subjects in this group had stage III or IV disease at the time of surgery. Additionally, 3-year survival was improved in the multimodality group ( $32 \%$ vs $6 \%$ ), and median survival was significantly longer in the multimodality group (16 vs 11 months). Weaknesses of this study included the poor rate of survival in the surgery monotherapy group, as well as the inclusion of some gastric cardia cancers in the study group.

A second study performed at University of Michigan showed less conclusive data. ${ }^{52}$ This randomized controlled trial of 100 patients with both squamous cell carcinoma and adenocarcinoma of the esophagus compared surgery vs radiation combined with a chemotherapy regimen of 5-fluorouracil, cisplatin, and vinblastine. Unlike the study by Walsh et al, ${ }^{51}$ this study showed only an insignificant trend toward improved survival at 3 years in the multimodality group $(30 \%$ vs $16 \% ; P=$ $.15)$. The absolute difference between the groups, although not statistically significant, is certainly clinically significant, but the study was not powered to detect relatively small absolute differences in survival.

Given the conflicting nature of the data, as well as the shortcomings of the studies considering this question, many centers continue to practice multimodality neoadjuvant therapy for subjects with adenocarcinoma of the esophagus. Although some authorities have divergent points of view ${ }^{53,54}$ and although other data suggest no 


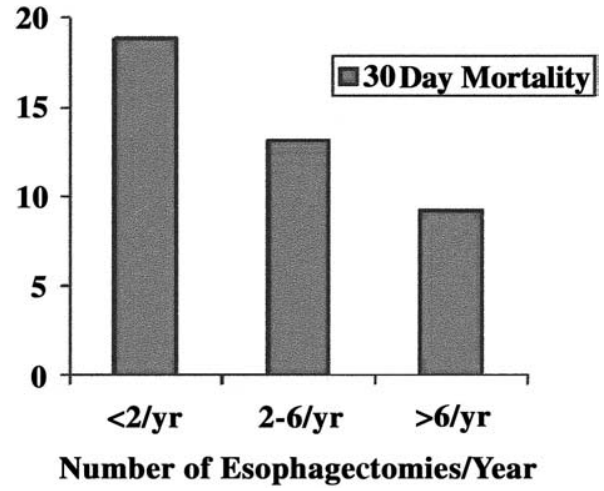

Figure 1. Thirty-day mortality of surgical esophagectomy as a function of the experience of the surgeon. Mortality approximately doubles from relatively inexperienced surgeons to high-volume practitioners. (Data adapted from Birkmeyer et al. ${ }^{59}$ )

benefit from neoadjuvant therapy in the setting of esophageal adenocarcinoma, ${ }^{55}$ given the low likelihood of complete resection of disease in the absence of neoadjuvant therapy, this practice will likely continue in the absence of further definitive data.

Also becoming better understood is the optimal surgical approach to resection of cancer. Radical en bloc resection includes a laparotomy, a thoracotomy, and a cervical approach. This approach allows for extensive lymph node sampling and good assessment of extent of disease. Alternatively, transhiatal approaches involve dissection of the esophagus solely by use of abdominal and cervical approaches, thus obviating thoracotomy. A recent randomized controlled trial of the 2 approaches showed that neither was statistically superior to the other in 5-year survival, although the en bloc methods did provide an insignificant trend toward improved survival (39\% for en bloc and $29 \%$ for transhiatal). ${ }^{56}$ These results show that surgical approach is not a major predictor of survival and that individual factors, such as preoperative assessment of extent of disease and patient comorbidities, may best decide which approach is most appropriate. For instance, transhiatal resection might be most appropriate for the elderly patient with limited disease, whereas a more aggressive approach might be adopted in the younger, healthier patient with more extensive disease.

Perhaps the clearest message from the surgical literature is that the experience of the surgeon and the volume of the center providing the treatment are crucial predictors of the morbidity of the treatment. ${ }^{57,58}$ Low-volume surgeons have average 30-day mortality rates of $18.7 \%$ for esophagectomy, whereas high-volume surgeons have corresponding rates ${ }^{59}$ of $9.2 \%$ (Figure 1). These differences are likely due both to the greater experience of the surgical operators and to the specialized institutional support—such as skilled nursing, respiratory therapy, and intensive care units - that evolves in high volume centers. Morbidity for this procedure is also impressive, and serious postsurgical complications have been reported in more than $50 \%$ of subjects in some series. ${ }^{60,61}$ In addition to the perioperative risks noted previously, the propensity of the esophageal remnant to develop recurrent $\mathrm{BE}$ above the anastomosis is becoming better recognized. Studies of subjects after esophagectomy show that $47 \%$ have some columnar epithelium in the tubular esophagus and that approximately $10 \%$ develop BE. ${ }^{62,63}$

\section{What Is the Best Treatment for High-Grade Dysplasia?}

Given the uniformly poor survival reported in series of patients with esophageal adenocarcinoma presenting symptomatically, many centers in the United States have developed endoscopic surveillance programs for patients with BE. Subjects are endoscopically assessed at fixed intervals, and intervention is contemplated on the basis of the degree of dysplasia noted on surveillance biopsies. Subjects with nondysplastic BE are generally followed up at intervals of 2-3 years, whereas those with HGD are considered for intervention. ${ }^{64}$ Of current debate is the most appropriate care for those with HGD.

The presence of HGD is considered an appropriate criterion for surgical resection in many medical centers. Proponents of this position cite the high risk of progression, as well as the likelihood of metachronous cancer, as noted previously. ${ }^{37,65-69}$ Recently, 2 other potential management strategies have been put forward. Intensive endoscopic surveillance relies on the principle that superficial adenocarcinoma of the esophagus rarely has lymph node involvement. Therefore, if early detection efforts are rigorous enough, survival should not be negatively affected even if a substantial proportion of the cohort does progress to cancer. These subjects would go on to get the surgery that they would have gotten anyway and to be cured of disease, whereas the remainder of the cohort is spared a morbid surgery and the subsequent attendant decrease in quality of life from living after esophagectomy. To date, only 1 large cohort has been reported with this approach. Seventy-five subjects with HGD were followed up by Schnell et $\mathrm{al}^{38}$ with intensive endoscopic surveillance in a cohort study at the Hines Veterans Administration in Chicago. These subjects underwent intensive endoscopic surveillance (every 3 months for the first year, every 6 months for the second year, and yearly thereafter). At a mean follow-up of 7.3 years, only $16 \%$ of the cohort had developed cancer. The remainder of the group was cancer free with the esophagus intact. Twenty-one members of the cohort had died 
over that time, but only a single person had died from metastatic esophageal cancer. This individual was a patient who had been lost to follow-up for 10 years after his diagnosis of HGD and who presented after that period with widely metastatic disease.

It is unclear why the prognosis of HGD in the Hines Veterans Administration cohort was superior to that in other previously reported groups with HGD. ${ }^{34}$ Because this cohort underwent an extensive search for metachronous cancer before patients were enrolled in the surveillance program, some of the difference may be more apparent than actual-the group was better "purified" of metachronous cancer than other reported cohorts. Other alternative explanations include the possibility that variability between centers in the histological definition of HGD might explain these results. Certainly, if the Hines Veterans Administration patients with HGD had a less severe form of dysplasia than HGD patients in other cohorts, this finding might explain the discrepancy in the data. Regardless of these issues, on the basis of these data, some centers have been offering intensive endoscopic surveillance as an alternative to resection. This approach might be an especially attractive option in subjects who are poor surgical candidates or who are elderly. In such subjects, who might be most prone to a complication from interventions such as surgery or ablative therapy, intervention (and the risks associated with it) could be targeted to only that subgroup who went on to develop superficial cancer. Also, unifocal HGD (ie, HGD found on only 1 of a number of biopsy samples taken for endoscopic surveillance) might have a better prognosis than multifocal HGD. ${ }^{70}$ If so, perhaps unifocality of disease might be a reasonable criterion for considering intensive endoscopic surveillance.

One rapidly evolving area of investigation in the treatment of HGD is the use of endoscopic ablative therapies. These modalities offer the promise of diminishing the cancer risk in the setting of HGD while avoiding the morbidity and mortality of esophagectomy.

Multiple different modalities have been described, including electrocoagulation therapy, lasers, ${ }^{71-73}$ argon beam coagulation therapy, ${ }^{74-76}$ yttrium-aluminum-garnet laser therapy, ${ }^{77,78}$ radiofrequency ablation, ${ }^{79}$ and photodynamic therapy (PDT). ${ }^{80,81}$ Of all the modalities available, perhaps the most extensive available experience in the literature is with PDT. PDT relies on the interaction of a chemical compound, porfimer sodium, with light of a specific wavelength $(630 \mathrm{~nm})$ to cause an intracellular reaction that results in the death of the cell. Treatment of the affected segment of BE for a preset period of time results in a predictable degree of tissue damage, such that tissue destruction is deep enough to destroy most or all of the BE cells but not deep enough to cause full-thickness necrosis of the esophagus with subsequent perforation (Figure 2).

A controlled trial of subjects randomized to either PDT therapy with high-dose proton pump inhibition or proton pump inhibition alone has recently been performed. ${ }^{82}$ All subjects in the study had BE with HGD. This study, the result of which is currently available only in abstract form, shows a greater than $50 \%$ reduction in the number of subjects who developed adenocarcinoma in the group treated with PDT ( $28 \%$ vs $13 \% ; P=.006)$ Given these data, as well as uncontrolled data suggesting that ablation of HGD provides diminution of the cancer risk compared with historical controls, ${ }^{81}$ PDT has been approved by the US Food and Drug Administration as a treatment of BE with HGD.

Two conflicting concerns regarding the performance of PDT are the subsequent stricture rate in subjects undergoing the procedure and the likelihood of submucosal Barrett's glands under the neosquamous epithelium. These concerns are in a way complementary-ablative modalities that provide the deepest mucosal burn, such as PDT, feature relatively low rates of buried glands but higher rates of stricture. The opposite seems true of more superficial treatments of $\mathrm{BE}$, such as argon beam coagulation, which are associated with a lesser rate of stricturing but more buried glands. ${ }^{83}$ The stricture rate associated with 1 treatment of PDT approximates $20 \%$ and increases to approximately $50 \%$ if multiple treatments are necessary. ${ }^{81,84}$ These strictures are amenable to endoscopic therapy, but, because the strictures are thick and fibrous, multiple sessions of dilation may be necessary before good relief of dysphagia is obtained. Concomitant therapy with steroids does not decrease the subsequent stricture rate in subjects undergoing PDT. ${ }^{80}$ The rate of retained buried Barrett's glands under normal-appearing squamous mucosa is less well described. Clearly, these glands have the potential to progress through stages of dysplasia to cancer, because several case reports of submucosal adenocarcinoma in subjects with apparently normal neosquamous epithelium have been described. ${ }^{85-87}$ Whether the neosquamous epithelium itself has an increased risk of squamous cancer is similarly unclear.

Given the current state of the data, a reasonable approach to the patient with HGD might be consideration of either ablative therapy or intensive surveillance for those with unifocal disease. For those with multifocal disease, ablative therapy or surgical resection might be more appropriate. 

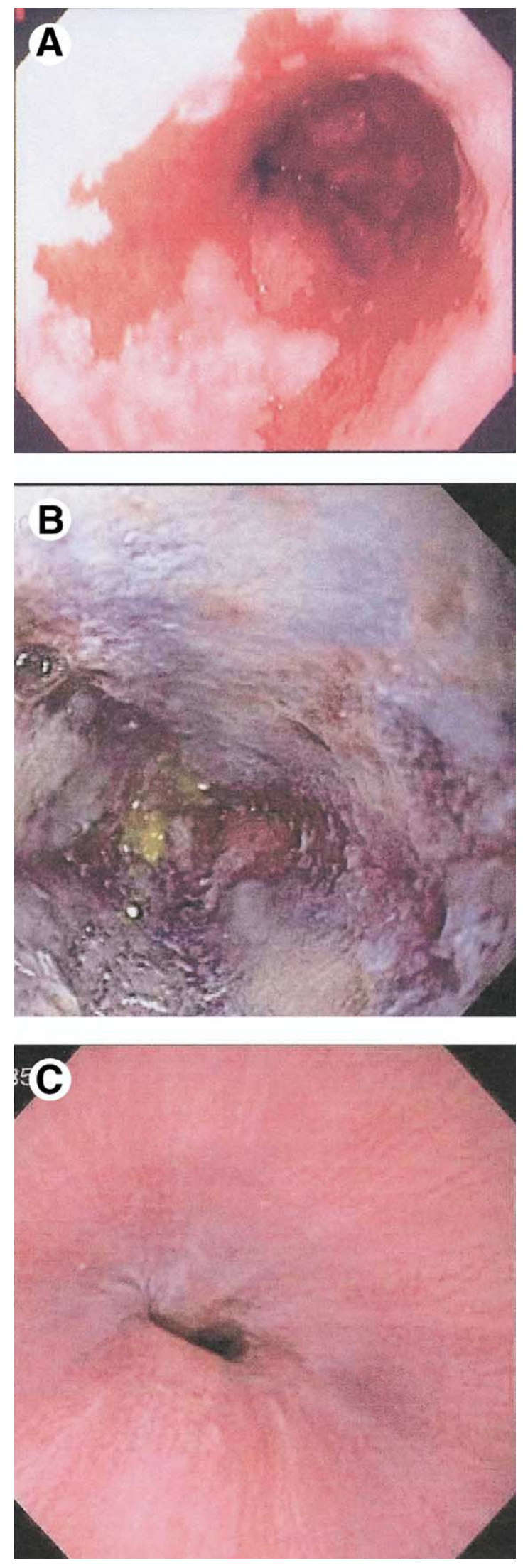

\section{Endoscopic Mucosal Resection: An Evolving Place in the Treatment Armamentarium}

Because of the morbidity and mortality associated with esophagectomy, as noted previously, investigators have become increasingly bold in their efforts at endoluminal therapy for superficial esophageal cancers and polypoid HGD. Endoscopic mucosal resection (EMR) offers the promise of definitive treatment of these lesions with a less invasive approach than thoracotomy. Several different endoscopic techniques have been developed. Piecemeal resection using a saline lift technique imitates the technique used for sessile colonic adenomas. ${ }^{88}$ This lift technique can be used in association with snare removal of the lesion. Other lesions may be amenable to resection with a banding technique similar to that used for esophageal varices; a snare is used to remove the pseudopolyp produced after banding so that the specimen can be sent to pathology to ensure complete removal. ${ }^{88-90}$ Finally, novel EMR resection caps, with a beveled edge and a snare that fits along a groove at the top of the cap, have been described. ${ }^{91}$ These caps may be positioned over the lesion of interest, after which suction is applied, and the lesion is pulled into the cap. The snare is tightened over the base of the lesion, which is then truncated. This method is especially useful for larger lesions, which will not easily fit in a variceal ligation cap.

Reports regarding the success of EMR at removing superficial lesions have been largely positive; however, the evidence to date consists of mostly case series, and publication bias may inflate the value of these procedures. Multiple endoscopic procedures may be necessary to accomplish complete removal of the lesion. With respect to the recurrence of cancer, most series report little or no progression to more advanced cancer. However, it should be noted that most reported series noted previously feature a mean follow-up of less than 24 months.

Recently, attempts have been made to treat large portions of mucosa with HGD but no masses or nodules by using EMR to remove portions of columnar epithelium, as opposed to discrete lesions. ${ }^{92}$ Although preliminary experience with these techniques has been encouraging, the relatively large portions of the mucosa that require resection, as well as the preliminary nature of

Figure 2. Typical findings in photodynamic therapy for Barrett's esophagus. (A) A typical segment of BE with HGD. (B) Extensive mucosal necrosis is evident 48 hours after application of the laser to the mucosa, which was pretreated with photofrin. $(C)$ The area of previous BE 3 months later, now epithelialized with normal squamous mucosa. 
these reports, make total removal of $\mathrm{BE}$ by endoscopic resection a procedure best performed as part of a clinical trial. Currently, large-scale EMR of nonnodular BE is not recommended as a standard practice.

\section{Chemoprevention of Esophageal Adenocarcinoma}

Extensive observational data substantiate that nonsteroidal anti-inflammatory drugs (NSAIDs) are associated with a $50 \%$ or greater decrease in esophageal cancer. ${ }^{93-96}$ The exact mechanism of any chemopreventive effect is unclear, and no randomized controlled trial has confirmed that this observed association is causative. However, given the poor prognosis associated with esophageal cancer, authorities have suggested the potential use of chemoprevention in the setting of BE. ${ }^{97}$ Especially in subjects with HGD, such chemoprevention, if effective, might markedly reduce the risk of cancer. Indeed, cost-effectiveness analyses have suggested that chemoprevention for HGD might be a very cost-effective maneuver. A recent cost-effectiveness model ${ }^{98}$ examining the utility of aspirin as a chemopreventive agent in association with surveillance endoscopy showed that, compared with no therapy, an additional quality-adjusted life-year could be obtained for an acceptable cost of $\$ 49,600$. A second analysis also suggested that chemoprevention with NSAIDs provided gains in life expectancy at potentially reasonable costs. ${ }^{99}$ These calculations assume, of course, that NSAID use retards the progression of HGD to cancer. If the actual mechanism of chemoprevention of cancer by NSAIDs is to prevent the initial formation of BE, it may well be that attempts at treating HGD with NSAIDs to stop cancer are fruitless, because the critical point for intervention has already been missed. Recent work has concentrated on the potential use of cyclooxygenase 2 inhibitors as chemopreventive agents. It was hoped that a superior side-effect profile of these agents compared with nonselective NSAIDs might improve the risk-benefit ratio of chemoprevention. However, given recent revelations about potential cardiac side effects with rofecoxib, ${ }^{100}$ the use of cyclooxygenase 2 inhibitors as chemoprevention in the setting of BE is not currently advisable.

Another recent topic of interest has been the effect of rigorous acid inhibition with proton pump inhibitors on the natural history of BE. Early after the advent of proton pump inhibitors, multiple studies showed that proton pump inhibitor therapy did not lead to the reliable regression of BE. ${ }^{101-103}$ Recently, however, longitudinal cohort studies of subjects with BE have suggested that the use of proton pump inhibitors may be associated with a decreased risk of dysplasia in the $\mathrm{BE}^{104,105}$ (Figure 3). In vitro work suggests that pulsed acid exposure promotes proliferation of cell cultures of BE. ${ }^{106}$ It may be that the chronic inflammation associated with ongoing GERD promotes carcinogenesis. If so, then acid suppression of subjects with $\mathrm{BE}$ may retard the progression to cancer. It is unclear presently whether subjects with $\mathrm{BE}$ need to undergo acid suppression to the point of complete obliteration of esophageal acid exposure or whether less rigorous acid suppression will still confer any benefits against progression of disease. Although the effect of vigorous acid suppression on the likelihood of progression of BE is unclear, the common occurrence of reflux symptoms in these patients and the benign nature of the intervention make it reasonable to maintain these patients on acid suppression with a proton pump inhibitor.

\section{Does Endoscopic Screening of Subjects With Chronic Gastroesophageal Reflux Disease Symptoms Prevent Death From Esophageal Adenocarcinoma?}

Endoscopic screening of subjects with chronic GERD symptoms has been proposed as a method for detecting subclinical cancers, as well as BE. Subjects found to harbor BE could then be entered into surveillance programs designed to monitor the lesion for progression. ${ }^{64}$ Although data in support of the efficacy of this approach are lacking, the practice is widespread among gastroenterologists. ${ }^{107}$

Recommending organizations are somewhat conflicted as to the appropriate approach for screening subjects with

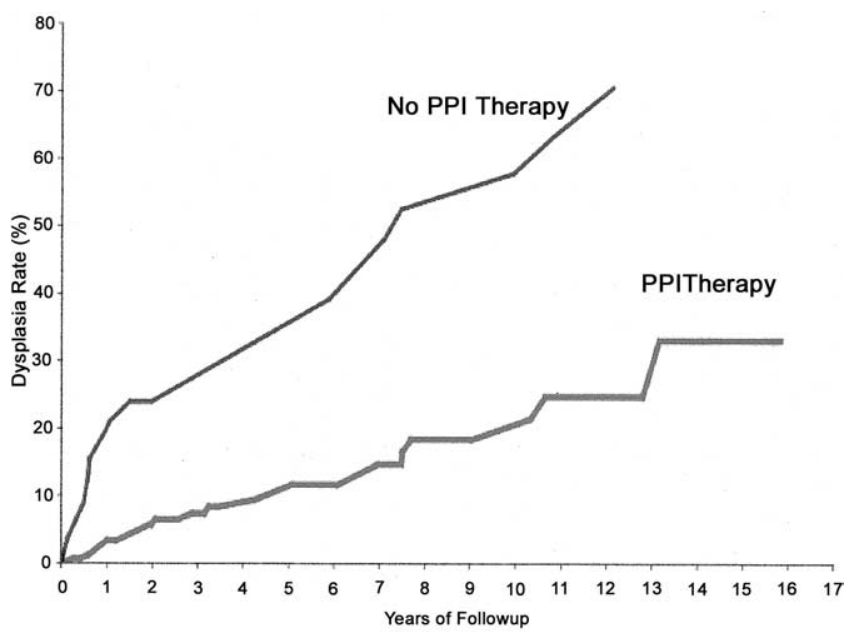

Figure 3. Dysplasia risk as a function of acid-suppressive therapy. In 236 US veterans with nondysplastic BE, El-Serag et al. ${ }^{105}$ showed that protection from dysplasia development was strongly associated with proton pump inhibitor (PPI) therapy (Reprinted from the American Journal of Gastroenterology, Saunders, published with permission). 
chronic GERD. The Practice Parameters Committee of the American College of Gastroenterology notes in their most recent guidelines that "patients with chronic GERD symptoms are those most likely to have Barrett's esophagus and should undergo upper endoscopy." 64 This once-in-a-lifetime endoscopy would screen for BE and allow enrollment of eligible subjects into surveillance protocols. Conversely, at a recent American College of Gastroenterology Consensus Conference, a multidisciplinary panel of 18 experts in BE believed that there was insufficient evidence to accept the proposition that screening for BE improved mortality from adenocarcinoma or was cost-effective. ${ }^{108}$ Contrary to the American College of Gastroenterology clinical guidelines, the American College of Gastroenterology participants did not believe that adequate data were available to support screening for adults over older than 50 years, regardless of age or duration of heartburn.

The source of this discrepancy of opinion lies in the lack of convincing data to show any beneficial effect of screening endoscopy, as well as the substantial theoretical concerns about the effectiveness and cost-effectiveness about such an approach. The data supporting screening upper endoscopy are weak. Patients who have their cancers detected as part of an endoscopic screening and surveillance program have their lesions discovered at an earlier stage and are more often eligible for surgical resection. Also, the life expectancy of individuals with esophageal adenocarcinoma diagnosed by endoscopic screening programs is longer than the life expectancy of those who present symptomatically. ${ }^{109-114}$ Although data such as these seem suggestive, several biases, including lead-time and length bias, ${ }^{115,116}$ often accentuate the apparent benefits of endoscopic screening and surveillance programs in observational studies. Therefore, the only available data supporting screening endoscopy are observational and subject to bias.

However, substantial theoretical concerns argue against the effectiveness of screening upper endoscopy for those with GERD. First, the ubiquity of GERD in the United States means that the pool of subjects to be screened is enormous. Even if we limit potential screenees to those older than the age of 55 years with at least weekly GERD symptoms, according to US census statistics and our knowledge of the epidemiology of GERD, more than 10 million subjects in the United States would be eligible for screening (Figure $4)$. Second, the cancer that we are trying to prevent is relatively rare; a little more than half of the 14,250 cases of esophageal cancer in the United States in 2004 are expected to be adenocarcinomas. ${ }^{17}$ Third, a large portion of those with adenocarcinoma never experience significant reflux symptoms. Case-control studies suggest that approximately $40 \%$ of those with adenocarcinoma never experienced reflux symptoms before their cancer diagnosis. ${ }^{15,16}$ Clearly this group would not benefit from screening programs aimed at those subjects with reflux symptoms. Next, the age of onset for this cancer in most series is in excess of 70 years. Many patients of that age have significant comorbidities that make effective intervention difficult and limit the number of life-years that can be saved even if effective intervention is attained. ${ }^{15,118}$ In fact, longitudinal studies show that those with BE have the same survival as age- and sex-matched controls without $\mathrm{BE}$ from the general public. ${ }^{119,120}$ Finally, even if upper endoscopy is obtained before the diagnosis of cancer, $\mathrm{BE}$ might not be correctly identified, and the subject might not be entered in a surveillance program. In a recent retrospective cohort study in the Kaiser Permanente group in California, out of 64 patients who developed adenocarcinoma and had an upper endoscopy before the development of cancer, only 23 had identification of BE. ${ }^{121}$ Whether short segments of $\mathrm{BE}$ were missed on endoscopy in the remaining $64 \%$ of patients or whether their cancer did not originate in segments of BE is unknown.

These barriers to effective screening are compounded by the fact that our screening test, upper endoscopy, is relatively expensive. Also, although it is a very safe test, because the yield with respect to cancer is so low, the number of cancers averted may be rivaled by the number of complications of endoscopy. ${ }^{122-125}$ Although some cost analyses have suggested that screening and surveillance may be costeffective, ${ }^{126,127}$ the authors note that the results of these analyses are sensitive to several poorly defined variables. It is interesting to note that 1 recent analysis suggested that although an initial endoscopic screening looking for $\mathrm{BE}$ with dysplasia was costeffective, subsequent endoscopic surveillance of subjects with nondysplastic BE was highly cost-prohibitive. ${ }^{128}$

At this juncture, it is highly unlikely in the United States that a randomized trial of endoscopic screening and surveillance vs usual symptomatic care of GERD will ever be performed. However, data may become available from other countries where endoscopic screening and surveillance are not widely practiced. In the meantime, clinicians will need to weigh the risks and possible benefits of screening on a case-by-case basis, and all decisions on the subject should be prefaced with a frank discussion with the patient about the lack of hard evidence for the practice. More targeted 


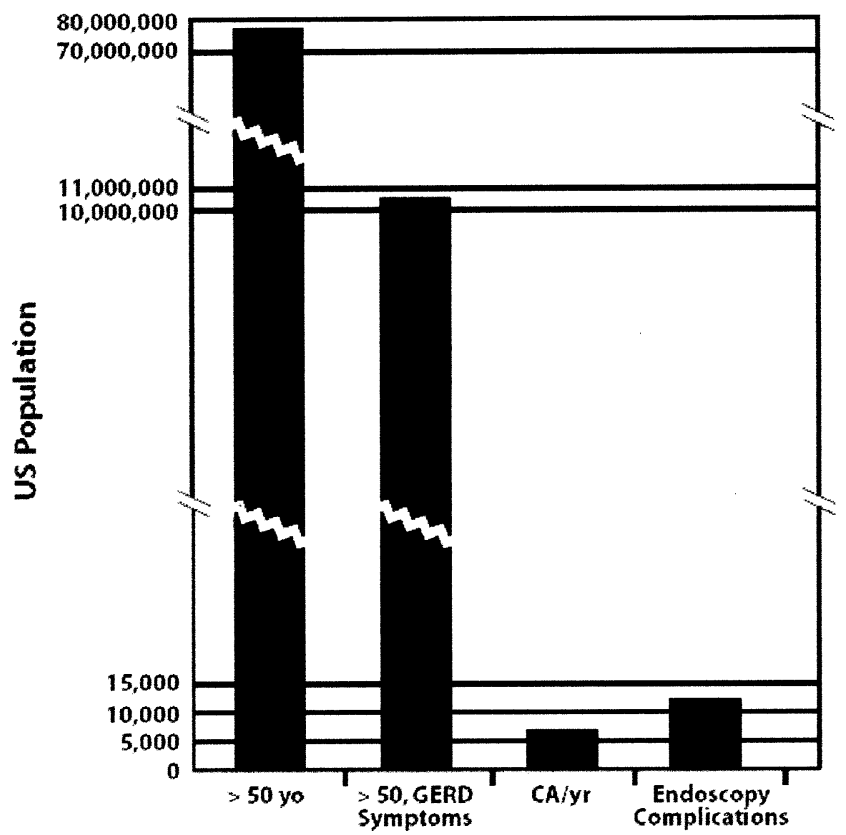

Figure 4. Performance of a hypothetical national screening program for esophageal adenocarcinoma. Given the vast number of subjects with chronic GERD symptoms who would need to be screened, even if we limited our screening to those older than the age of 50 years, more than 10 million Americans might be eligible for screening. We know that the absolute number of cancers approximates 8000 per year and that almost half of these occur in subjects without significant chronic GERD. Although upper endoscopy is a safe procedure, such a program might have more major endoscopy complications than cancers discovered (data adapted from Shaheen and Ransohoff ${ }^{130}$ ). CA, cancer; yo, years old.

screening, perhaps aimed at high-prevalence subgroups, ${ }^{129}$ may improve the effectiveness of these practices.

\section{Conclusion}

Despite some strides in our understanding of the pathophysiology and treatment of the disease, esophageal adenocarcinoma remains a deadly tumor. Although it is rare in the United States, the incidence of this disease has increased rapidly in the last 40 years, commanding the attention of clinicians and makers of public health policy. Many centers specializing in the care of this cancer perform neoadjuvant chemoradiation, although the benefits of this approach are unclear. In an effort to avoid the morbidity associated with esophagectomy, rapid evolution has occurred in the endoscopic treatments of superficial adenocarcinoma and BE with HGD. Although the results of these techniques are promising, most follow-up to date is short-term, and the effectiveness of these therapies is not fully elucidated.

Although chemoprevention in the setting of $\mathrm{BE}$ with NSAIDs, proton pump inhibitors, or both may be of benefit, randomized data are lacking to prove this. Because most subjects with BE undergo initial investigation because of GERD symptoms, proton pump inhibitor therapy, both for symptomatic relief and any benefit conferred from slowing progression to dysplasia, seems warranted in subjects with BE. Although widely practiced, endoscopic screening of those with chronic GERD symptoms, with enrollment of subjects with BE into endoscopic surveillance programs, is of unclear benefit.

\section{References}

1. Daly JM, Karnell LH, Menck HR. National Cancer Data Base report on esophageal carcinoma. Cancer 1996;78:1820-1828.

2. Bytzer $P$, Christensen $P B$, Damkier $P$, Vinding $K$, Seersholm $N$. Adenocarcinoma of the esophagus and Barrett's esophagus: a population-based study. Am J Gastroenterol 1999;94:86-91.

3. Devesa SS, Blot WJ, Fraumeni JF Jr. Changing patterns in the incidence of esophageal and gastric carcinoma in the United States. Cancer 1998;83:2049-2053.

4. Corley DA, Kubo A. Influence of site classification on cancer incidence rates: an analysis of gastric cardia carcinomas. J Natl Cancer Inst 2004;96:1383-1387.

5. Nguyen AM, Luke CG, Roder D. Comparative epidemiological characteristics of oesophageal adenocarcinoma and other cancers of the oesophagus and gastric cardia. Asian Pac J Cancer Prev 2003;4:225-231.

6. Conio M, Cameron AJ, Romero Y, Branch CD, Schleck CD, Burgart LJ, et al. Secular trends in the epidemiology and outcome of Barrett's oesophagus in Olmsted County, Minnesota. Gut 2001;48:304-309.

7. Hurschler D, Borovicka J, Neuweiler J, Oehlschlegel C, Sagmeister $\mathrm{M}$, Meyenberger $\mathrm{C}$, et al. Increased detection rates of Barrett's oesophagus without rise in incidence of oesophageal adenocarcinoma. Swiss Med Wkly 2003;133:507-514.

8. Kuczmarski RJ, Flegal KM, Campbell SM, Johnson CL. Increasing prevalence of overweight among US adults. The National Health and Nutrition Examination Surveys, 1960 to 1991. JAMA 1994;272:205-211.

9. Mokdad AH, Serdula MK, Dietz WH, Bowman BA, Marks JS, Koplan JP. The spread of the obesity epidemic in the United States, 1991-1998. JAMA 1999;282:1519-1522.

10. Lagergren J, Bergstrom R, Nyren O. Association between body mass and adenocarcinoma of the esophagus and gastric cardia. Ann Intern Med 1999;130:883-890.

11. Chow WH, Blot WJ, Vaughan TL, Risch HA, Gammon MD, Stanford JL, et al. Body mass index and risk of adenocarcinomas of the esophagus and gastric cardia. J Natl Cancer Inst 1998;90: 150-155.

12. Engel LS, Chow WH, Vaughan TL, Gammon MD, Risch HA, Stanford JL, et al. Population attributable risks of esophageal and gastric cancers. J Natl Cancer Inst 2003;95:1404-1413.

13. Wei JT, Shaheen N. The changing epidemiology of esophageal adenocarcinoma. Semin Gastrointest Dis 2003;14:112-127.

14. El Serag HB. The epidemic of esophageal adenocarcinoma. Gastroenterol Clin North Am 2002;31:421-440, viii.

15. Lagergren J, Bergstrom R, Lindgren A, Nyren O. Symptomatic gastroesophageal reflux as a risk factor for esophageal adenocarcinoma. N Engl J Med 1999;340:825-831.

16. Farrow DC, Vaughan TL, Sweeney C, Gammon MD, Chow WH, Risch HA, et al. Gastroesophageal reflux disease, use of H2 receptor antagonists, and risk of esophageal and gastric cancer. Cancer Causes Control 2000;11:231-238. 
17. Chow WH, Finkle WD, McLaughlin JK, Frankl H, Ziel HK, Fraumeni JF Jr. The relation of gastroesophageal reflux disease and its treatment to adenocarcinomas of the esophagus and gastric cardia. JAMA 1995;274:474-477.

18. Gerson LB, Shetler K, Triadafilopoulos G. Prevalence of Barrett's esophagus in asymptomatic individuals. Gastroenterology 2002;123:461-467.

19. Rex DK, Cummings OW, Shaw M, Cumings MD, Wong RK, Vasudeva RS, et al. Screening for Barrett's esophagus in colonoscopy patients with and without heartburn. Gastroenterology 2003;125:1670-1677.

20. DeVault KR, Ward EM, Wolfsen HC, Loeb DS, Krishna M, Hemminger LL, et al. Barrett's esophagus is common in older patients undergoing screening colonoscopy regardless of gastroesophageal reflux symptoms (abstr). Gastroenterology 2004; 126(Suppl 2):680A.

21. O'Connor JB, Falk GW, Richter JE. The incidence of adenocarcinoma and dysplasia in Barrett's esophagus: report on the Cleveland Clinic Barrett's Esophagus Registry. Am J Gastroenterol 1999;94:2037-2042.

22. Drewitz DJ, Sampliner RE, Garewal HS. The incidence of adenocarcinoma in Barrett's esophagus: a prospective study of 170 patients followed 4.8 years. Am J Gastroenterol 1997;92:212215.

23. Conio M, Blanchi S, Lapertosa G, Ferraris R, Sablich R, Marchi $S$, et al. Long-term endoscopic surveillance of patients with Barrett's esophagus. Incidence of dysplasia and adenocarcinoma: a prospective study. Am J Gastroenterol 2003;98:19311939.

24. Shaheen NJ, Crosby MA, Bozymski EM, Sandler RS. Is there publication bias in the reporting of cancer risk in Barrett's esophagus? Gastroenterology 2000;119:333-338.

25. Corder AP, Jones RH, Sadler GH, Daniels P, Johnson CD. Heartburn, oesophagitis and Barrett's oesophagus in self-medicating patients in general practice. Br J Clin Pract 1996;50:245-248.

26. Winters C Jr, Spurling TJ, Chobanian SJ, Curtis DJ, Esposito RL, Hacker JF III, et al. Barrett's esophagus. A prevalent, occult complication of gastroesophageal reflux disease. Gastroenterology 1987;92:118-124.

27. Csendes A, Smok G, Burdiles P, Quesada F, Huertas C, Rojas J, et al. Prevalence of Barrett's esophagus by endoscopy and histologic studies: a prospective evaluation of 306 control subjects and 376 patients with symptoms of gastroesophageal reflux. Dis Esophagus 2000;13:5-11.

28. Chak A, Lee T, Kinnard MF, Brock W, Faulx A, Willis J, et al. Familial aggregation of Barrett's oesophagus, oesophageal adenocarcinoma, and oesophagogastric junctional adenocarcinoma in Caucasian adults. Gut 2002;51:323-328.

29. Romero Y, Cameron AJ, Schaid DJ, McDonnell SK, Burgart LJ, Hardtke CL, et al. Barrett's esophagus: prevalence in symptomatic relatives. Am J Gastroenterol 2002;97:1127-1132.

30. Boch JA, Shields HM, Antonioli DA, Zwas F, Sawhney RA, Trier JS. Distribution of cytokeratin markers in Barrett's specialized columnar epithelium. Gastroenterology 1997;112:760-765.

31. Shields HM, Rosenberg SJ, Zwas FR, Ransil BJ, Lembo AJ, Odze R. Prospective evaluation of multilayered epithelium in Barrett's esophagus. Am J Gastroenterol 2001;96:3268-3273.

32. Sarosi G, Brown G, Jaiswal K, Lee E, Crook T, Sousa R, et al. Reflux-damaged epithelium is replaced by cells derived from the bone marrow in a rat model of Barrett's esophagus (abstr). Gastroenterology 2004;126(Suppl 2):307A.

33. Miros $M$, Kerlin P, Walker N. Only patients with dysplasia progress to adenocarcinoma in Barrett's oesophagus. Gut 1991;32:1441-1446.

34. Reid BJ, Levine DS, Longton G, Blount PL, Rabinovitch PS. Predictors of progression to cancer in Barrett's esophagus: baseline histology and flow cytometry identify low- and high-risk patient subsets. Am J Gastroenterol 2000;95:1669-1676.

35. Falk GW, Rice TW, Goldblum JR, Richter JE. Jumbo biopsy forceps protocol still misses unsuspected cancer in Barrett's esophagus with high-grade dysplasia. Gastrointest Endosc 1999;49:170-176.

36. Cameron AJ, Carpenter HA. Barrett's esophagus, high-grade dysplasia, and early adenocarcinoma: a pathological study. Am J Gastroenterol 1997;92:586-591.

37. Heitmiller RF, Redmond M, Hamilton SR. Barrett's esophagus with high-grade dysplasia. An indication for prophylactic esophagectomy. Ann Surg 1996;224:66-71.

38. Schnell TG, Sontag SJ, Chejfec G, Aranha G, Metz A, O'Connell $S$, et al. Long-term nonsurgical management of Barrett's esophagus with high-grade dysplasia. Gastroenterology 2001;120: 1607-1619.

39. Kiesslich R, Hahn M, Herrmann G, Jung M. Screening for specialized columnar epithelium with methylene blue: chromoendoscopy in patients with Barrett's esophagus and a normal control group. Gastrointest Endosc 2001;53:47-52.

40. Canto MI, Setrakian S, Petras RE, Blades E, Chak A, Sivak MV Jr. Methylene blue selectively stains intestinal metaplasia in Barrett's esophagus. Gastrointest Endosc 1996;44:1-7.

41. Canto MI, Setrakian S, Willis J, Chak A, Petras R, Powe NR, et al. Methylene blue-directed biopsies improve detection of intestinal metaplasia and dysplasia in Barrett's esophagus. Gastrointest Endosc 2000;51:560-568.

42. Sharma P, Weston AP, Topalovski M, Cherian R, Bhattacharyya A, Sampliner RE. Magnification chromoendoscopy for the detection of intestinal metaplasia and dysplasia in Barrett's oesophagus. Gut 2003;52:24-27.

43. Sihvo El, Luostarinen ME, Salo JA. Fate of patients with adenocarcinoma of the esophagus and the esophagogastric junction: a population-based analysis. Am J Gastroenterol 2004;99: 419-424.

44. Victorzon M, Tolonen P, Kohonen M, Salmo M. Outcome of surgery for oesophageal carcinoma in a low volume centre, with and without preoperative chemoradiotherapy. Scand J Surg 2004;93:37-42.

45. Hagen JA, DeMeester SR, Peters JH, Chandrasoma P, DeMeester TR. Curative resection for esophageal adenocarcinoma: analysis of 100 en bloc esophagectomies. Ann Surg 2001; 234:520-530.

46. Eloubeidi MA, Desmond R, Arguedas MR, Reed CE, Wilcox CM. Prognostic factors for the survival of patients with esophageal carcinoma in the U.S.: the importance of tumor length and lymph node status. Cancer 2002;95:1434-1443.

47. Kelsen DP, Ginsberg R, Pajak TF, Sheahan DG, Gunderson L, Mortimer J, et al. Chemotherapy followed by surgery compared with surgery alone for localized esophageal cancer. N Engl J Med 1998;339:1979-1984.

48. Forastiere AA, Orringer MB, Perez-Tamayo C, Urba SG, Zahurak M. Preoperative chemoradiation followed by transhiatal esophagectomy for carcinoma of the esophagus: final report. J Clin Oncol 1993;11:1118-1123.

49. Posner MC, Gooding WE, Landreneau RJ, Rosenstein MM, Clarke MR, Peterson MS, et al. Preoperative chemoradiotherapy for carcinoma of the esophagus and gastroesophageal junction. Cancer J Sci Am 1998;4:237-246.

50. Bates BA, Detterbeck FC, Bernard SA, Qaqish BF, Tepper JE. Concurrent radiation therapy and chemotherapy followed by esophagectomy for localized esophageal carcinoma. J Clin Oncol 1996;14:156-163.

51. Walsh TN, Noonan N, Hollywood D, Kelly A, Keeling N, Hennessy TP. A comparison of multimodal therapy and surgery for esophageal adenocarcinoma. N Engl J Med 1996;335:462-467. 
52. Urba SG, Orringer MB, Turrisi A, Iannettoni M, Forastiere A, Strawderman M. Randomized trial of preoperative chemoradiation versus surgery alone in patients with locoregional esophageal carcinoma. J Clin Oncol 2001;19:305-313.

53. Malthaner RA, Wong RK, Rumble RB, Zuraw L. Neoadjuvant or adjuvant therapy for resectable esophageal cancer: a clinical practice guideline. BMC Cancer 2004;4:67.

54. Stahl M. Adjuvant chemoradiotherapy in gastric cancer and carcinoma of the oesophago-gastric junction. Onkologie 2004; 27:33-36.

55. Donington JS, Miller DL, Allen MS, Deschamps C, Nichols FC III, Pairolero PC. Preoperative chemoradiation therapy does not improve early survival after esophagectomy for patients with clinical stage III adenocarcinoma of the esophagus. Ann Thorac Surg 2004;77:1193-1198.

56. Hulscher JB, van Sandick JW, de Boer AG, Wijnhoven BP, Tijssen $J G$, Fockens $P$, et al. Extended transthoracic resection compared with limited transhiatal resection for adenocarcinoma of the esophagus. N Engl J Med 2002;347:1662-1669.

57. Dimick JB, Pronovost PJ, Cowan JA Jr, Lipsett PA, Stanley JC, Upchurch GR Jr. Variation in postoperative complication rates after high-risk surgery in the United States. Surgery 2003;134: 534-540.

58. Urbach DR, Baxter NN. Does it matter what a hospital is "high volume" for? Specificity of hospital volume-outcome associations for surgical procedures: analysis of administrative data. BMJ 2004;328:737-740.

59. Birkmeyer JD, Siewers AE, Finlayson EV, Stukel TA, Lucas FL, Batista I, et al. Hospital volume and surgical mortality in the United States. N Engl J Med 2002;346:1128-1137.

60. Atkins BZ, Shah AS, Hutcheson KA, Mangum JH, Pappas TN, Harpole DH Jr, et al. Reducing hospital morbidity and mortality following esophagectomy. Ann Thorac Surg 2004;78:1170-1176.

61. Rice DC, Correa AM, Vaporciyan AA, Sodhi N, Smythe WR, Swisher SG, et al. Preoperative chemoradiotherapy prior to esophagectomy in elderly patients is not associated with increased morbidity. Ann Thorac Surg 2005;79:391-397.

62. Oberg S, Johansson J, Wenner J, Walther B. Metaplastic columnar mucosa in the cervical esophagus after esophagectomy. Ann Surg 2002;235:338-345.

63. Franchimont D, Covas A, Brasseur C, Laethem JL, El Nakadi I, Deviere J. Newly developed Barrett's esophagus after subtotal esophagectomy. Endoscopy 2003;35:850-853.

64. Sampliner RE. The Practice Parameters Committee of the American College of Gastroenterology. Updated guidelines for the diagnosis, surveillance, and therapy of Barrett's esophagus. Am J Gastroenterol 2002;97:1888-1895.

65. Tseng EE, Wu TT, Yeo CJ, Heitmiller RF. Barrett's esophagus with high grade dysplasia: surgical results and long-term outcome-an update. J Gastrointest Surg 2003;7:164-170.

66. Nigro JJ, Hagen JA, DeMeester TR, DeMeester SR, Theisen J, Peters $\mathrm{JH}$, et al. Occult esophageal adenocarcinoma: extent of disease and implications for effective therapy. Ann Surg 1999; 230:433-438.

67. Edwards MJ, Gable DR, Lentsch AB, Richardson JD. The rationale for esophagectomy as the optimal therapy for Barrett's esophagus with high-grade dysplasia. Ann Surg 1996;223:585-589.

68. Pera M, Trastek VF, Carpenter HA, Allen MS, Deschamps C, Pairolero PC. Barrett's esophagus with high-grade dysplasia: an indication for esophagectomy? Ann Thorac Surg 1992;54:199_ 204.

69. Rice TW, Falk GW, Achkar E, Petras RE. Surgical management of high-grade dysplasia in Barrett's esophagus. Am J Gastroenterol 1993;88:1832-1836.

70. Buttar NS, Wang KK, Sebo TJ, Riehle DM, Krishnadath KK, Lutzke LS, et al. Extent of high-grade dysplasia in Barrett's esophagus correlates with risk of adenocarcinoma. Gastroenterology 2001;120:1630-1639.

71. Barham CP, Jones RL, Biddlestone LR, Hardwick RH, Shepherd NA, Barr H. Photothermal laser ablation of Barrett's oesophagus: endoscopic and histological evidence of squamous reepithelialisation. Gut 1997;41:281-284.

72. McCarthy M, Wilkinson ML. Treatment of Barrett's esophagus by endoscopic laser ablation and antireflux surgery (erratum appears in Gastrointest Endosc 1999;50:966). Gastrointest Endosc 1999;49:129-130.

73. Fisher RS, Bromer MQ, Thomas RM, Cohen S, Krevsky B, Horwitz $\mathrm{B}$, et al. Predictors of recurrent specialized intestinal metaplasia after complete laser ablation. Am J Gastroenterol 2003; 98:1945-1951.

74. Dumoulin FL, Terjung B, Neubrand M, Scheurlen C, Fischer HP, Sauerbruch T. Treatment of Barrett's esophagus by endoscopic argon plasma coagulation. Endoscopy 1997;29:751-753.

75. Schulz H, Miehlke S, Antos D, Schentke KU, Vieth M, Stolte M, et al. Ablation of Barrett's epithelium by endoscopic argon plasma coagulation in combination with high-dose omeprazole. Gastrointest Endosc 2000;51:659-663.

76. Attwood SE, Lewis CJ, Caplin S, Hemming K, Armstrong G. Argon beam plasma coagulation as therapy for high-grade dysplasia in Barrett's esophagus. Clin Gastroenterol Hepatol 2003;1: 258263.

77. Norberto L, Polese L, Angriman I, Erroi F, Cecchetto A, D'Amico DF. High-energy laser therapy of Barrett's esophagus: preliminary results. World J Surg 2004;28:350-354.

78. Weston AP, Sharma P. Neodymium:yttrium-aluminum garnet contact laser ablation of Barrett's high grade dysplasia and early adenocarcinoma. Am J Gastroenterol 2002;97: 2998-3006.

79. Ganz RA, Utley DS, Stern RA, Jackson J, Batts KP, Termin P. Complete ablation of esophageal epithelium with a balloon-based bipolar electrode: a phased evaluation in the porcine and in the human esophagus. Gastrointest Endosc 2004;60:1002-1010.

80. Panjehpour M, Overholt BF, Haydek JM, Lee SG. Results of photodynamic therapy for ablation of dysplasia and early cancer in Barrett's esophagus and effect of oral steroids on stricture formation. Am J Gastroenterol 2000;95:2177-2184.

81. Overholt BF, Panjehpour M, Haydek JM. Photodynamic therapy for Barrett's esophagus: follow-up in 100 patients. Gastrointest Endosc 1999;49:1-7.

82. Overholt BF, Lightdale CJ, Wang K, Canto M. International, multicenter, partially blinded, randomised study of the efficacy of photodynamic therapy (PDT) using porfimer sodium (POR) for the ablation of high-grade dysplasia (HGD) in Barrett's esophagus (BE): results of a 24 month follow-up (abstr). Gastroenterology 2003;124(5):151A.

83. Ackroyd R, Tam W, Schoeman M, Devitt PG, Watson DI. Prospective randomized controlled trial of argon plasma coagulation ablation vs. endoscopic surveillance of patients with Barrett's esophagus after antireflux surgery. Gastrointest Endosc 2004;59:1-7.

84. Overholt BF, Panjehpour M, Halberg DL. Photodynamic therapy for Barrett's esophagus with dysplasia and/or early stage carcinoma: long-term results. Gastrointest Endosc 2003;58:183-188.

85. Macey N, Le Dreau G, Volant A, Vaucher C, Nousbaum JB, Gouerou $\mathrm{H}$, et al. Adenocarcinoma of the esophago-gastric junction arising after endoscopic laser photocoagulation ablation of the short segment of Barrett's esophagus. Gastroenterol Clin Biol 2001;25:204-206.

86. Shand A, Dallal H, Palmer K, Ghosh S, Maclntyre M. Adenocarcinoma arising in columnar lined oesophagus following treatment with argon plasma coagulation. Gut 2001;48:580-581. 
87. Van Laethem JL, Peny MO, Salmon I, Cremer M, Deviere J. Intramucosal adenocarcinoma arising under squamous re-epithelialisation of Barrett's oesophagus. Gut 2000;46:574-577.

88. Nijhawan PK, Wang KK. Endoscopic mucosal resection for lesions with endoscopic features suggestive of malignancy and high-grade dysplasia within Barrett's esophagus. Gastrointest Endosc 2000;52:328-332.

89. Ell C, May A, Gossner L, Pech O, Gunter E, Mayer G, et al. Endoscopic mucosal resection of early cancer and high-grade dysplasia in Barrett's esophagus. Gastroenterology 2000;118: 670-677.

90. Buttar NS, Wang KK, Lutzke LS, Krishnadath KK, Anderson MA. Combined endoscopic mucosal resection and photodynamic therapy for esophageal neoplasia within Barrett's esophagus. Gastrointest Endosc 2001;54:682-688.

91. Harada M, Nagashima R, Takeda H, Takahashi T. Endoscopic resection of adenocarcinoma arising in a tongue of Barrett's esophagus. Gastrointest Endosc 2000;52:427-429.

92. Seewald S, Akaraviputh T, Seitz U, Brand B, Groth S, Mendoza G, et al. Circumferential EMR and complete removal of Barrett's epithelium: a new approach to management of Barrett's esophagus containing high-grade intraepithelial neoplasia and intramucosal carcinoma. Gastrointest Endosc 2003;57: 854-859.

93. Gammon MD, Terry MB, Arber N, Chow WH, Risch HA, Vaughan TL, et al. Nonsteroidal anti-inflammatory drug use associated with reduced incidence of adenocarcinomas of the esophagus and gastric cardia that overexpress cyclin D1: a population-based study. Cancer Epidemiol Biomarkers Prev 2004;13:34-39.

94. Funkhouser EM, Sharp GB. Aspirin and reduced risk of esophageal carcinoma. Cancer 1995;76:1116-1119.

95. Farrow DC, Vaughan TL, Hansten PD, Stanford JL, Risch HA, Gammon MD, et al. Use of aspirin and other nonsteroidal antiinflammatory drugs and risk of esophageal and gastric cancer. Cancer Epidemiol Biomarkers Prev 1998;7:97-102.

96. Corley DA, Kerlikowske K, Verma R, Buffler P. Protective association of aspirin/NSAIDs and esophageal cancer: a systematic review and meta-analysis. Gastroenterology 2003;124:47-56.

97. Fennerty MB. Does chemoprevention of Barrett's esophagus using acid suppression and/or COX-2 inhibition prevent neoplastic progression? Rev Gastroenterol Disord 2002;2(Suppl 2):S30-S37.

98. Hur C, Nishioka NS, Gazelle GS. Cost-effectiveness of aspirin chemoprevention for Barrett's esophagus. J Natl Cancer Inst 2004;96:316-325.

99. Sonnenberg A, Fennerty MB. Medical decision analysis of chemoprevention against esophageal adenocarcinoma. Gastroenterology 2003;124:1758-1766.

100. Graham DJ, Campen D, Hui R, Spence M, Cheetham C, Levy G, et al. Risk of acute myocardial infarction and sudden cardiac death in patients treated with cyclo-oxygenase 2 selective and non-selective non-steroidal anti-inflammatory drugs: nested case-control study. Lancet 2005;365:475-481.

101. Peters FT, Ganesh S, Kuipers EJ, Sluiter WJ, Klinkenberg-Knol EC, Lamers CB, et al. Endoscopic regression of Barrett's oesophagus during omeprazole treatment: a randomised double blind study. Gut 1999;45:489-494.

102. Cooper BT, Neumann CS, Cox MA, Iqbal TH. Continuous treatment with omeprazole $20 \mathrm{mg}$ daily for up to 6 years in Barrett's oesophagus. Aliment Pharmacol Ther 1998;12:893-897.

103. Sharma P, Sampliner RE, Camargo E. Normalization of esophageal $\mathrm{pH}$ with high-dose proton pump inhibitor therapy does not result in regression of Barrett's esophagus. Am J Gastroenterol 1997;92:582-585.

104. Hillman LC, Chiragakis L, Shadbolt B, Kaye GL, Clarke AC. Proton-pump inhibitor therapy and the development of dysplasia in patients with Barrett's oesophagus. Med J Aust 2004;180:387-391.

105. El Serag HB, Aguirre TV, Davis S, Kuebeler M, Bhattacharyya A, Sampliner RE. Proton pump inhibitors are associated with reduced incidence of dysplasia in Barrett's esophagus. Am J Gastroenterol 2004;99:1877-1883.

106. Kaur BS, Triadafilopoulos G. Acid- and bile-induced PGE(2) release and hyperproliferation in Barrett's esophagus are COX-2 and PKC-epsilon dependent. Am J Physiol Gastrointest Liver Physiol 2002;283:G327-G334.

107. Falk GW, Ours TM, Richter JE. Practice patterns for surveillance of Barrett's esophagus in the United States. Gastrointest Endosc 2000;52:197-203.

108. Sharma P, McQuaid K, Dent J, Fennerty MB, Sampliner R, Spechler $S$, et al. A critical review of the diagnosis and management of Barrett's esophagus: the AGA Chicago Workshop. Gastroenterology 2004;127:310-330.

109. Streitz JMJ, Andrews CWJ, Ellis FH Jr. Endoscopic surveillance of Barrett's esophagus. Does it help? J Thorac Cardiovasc Surg 1993;105:383-387.

110. Skinner DB. En bloc resection for neoplasms of the esophagus and cardia. J Thorac Cardiovasc Surg 1983;85:59-71.

111. Cederqvist C, Nielsen J, Berthelsen A, Hansen HS. Cancer of the oesophagus. II. Therapy and outcome. Acta Chir Scand 1978;144:233-240.

112. Ellis FH Jr, Gibb SP, Watkins E Jr. Esophagogastrectomy. A safe, widely applicable, and expeditious form of palliation for patients with carcinoma of the esophagus and cardia. Ann Surg 1983; 198:531-540.

113. Galandiuk S, Hermann RE, Cosgrove DM, Gassman JJ. Cancer of the esophagus. The Cleveland Clinic experience. Ann Surg 1986;203:101-108.

114. DeMeester TR, Zaninotto G, Johansson KE. Selective therapeutic approach to cancer of the lower esophagus and cardia. J Thorac Cardiovasc Surg 1988;95:42-54.

115. Hennekens $\mathrm{CH}$, Buring JE. Epidemiology in medicine. Boston: Little Brown \& Co, 1987.

116. Shaheen NJ, Provenzale D, Sandler RS. Upper endoscopy as a screening and surveillance tool in esophageal adenocarcinoma: a review of the evidence. Am J Gastroenterol 2002;97:1319-1327.

117. Jemal A, Tiwari RC, Murray T, Ghafoor A, Samuels A, Ward E, et al. Cancer statistics, 2004. CA Cancer J Clin 2004;54:8-29.

118. van der Burgh A, Dees J, Hop WC, Van Blankenstein M. Oesophageal cancer is an uncommon cause of death in patients with Barrett's oesophagus. Gut 1996;39:5-8.

119. Anderson LA, Murray LJ, Murphy SJ, Fitzpatrick DA, Johnston BT, Watson RG, et al. Mortality in Barrett's oesophagus: results from a population based study. Gut 2003;52:10811084.

120. Eckardt VF, Kanzler G, Bernhard G. Life expectancy and cancer risk in patients with Barrett's esophagus: a prospective controlled investigation. Am J Med 2001;111:33-37.

121. Corley DA, Levin TR, Habel LA, Weiss NS, Buffler PA. Surveillance and survival in Barrett's adenocarcinomas: a populationbased study. Gastroenterology 2002;122:633-640.

122. Kavic SM, Basson MD. Complications of endoscopy. Am J Surg 2001;181:319-332.

123. Chan MF. Complications of upper gastrointestinal endoscopy. Gastrointest Endosc Clin North Am 1996;6:287-303.

124. Arrowsmith JB, Gerstman BB, Fleischer DE, Benjamin SB. Results from the American Society for Gastrointestinal Endoscopy/U.S. Food and Drug Administration collaborative study on complication rates and drug use during gastrointestinal endoscopy. Gastrointest Endosc 1991;37:421-427.

125. Hart R, Classen M. Complications of diagnostic gastrointestinal endoscopy. Endoscopy 1990;22:229-233. 
126. Provenzale D, Schmitt C, Wong JB. Barrett's esophagus: a new look at surveillance based on emerging estimates of cancer risk. Am J Gastroenterol 1999;94:2043-2053.

127. Sonnenberg A, Soni A, Sampliner RE. Medical decision analysis of endoscopic surveillance of Barrett's oesophagus to prevent oesophageal adenocarcinoma. Aliment Pharmacol Ther 2002;16: 41-50.

128. Inadomi JM, Sampliner R, Lagergren J, Lieberman D, Fendrick AM, Vakil N. Screening and surveillance for Barrett esophagus in high-risk groups: a cost-utility analysis. Ann Intern Med 2003; 138:176-186.

129. Caygill CP, Watson A, Reed PI, Hill MJ. Characteristics and regional variations of patients with Barrett's oesophagus in the UK. Eur J Gastroenterol Hepatol 2003;15:1217-1222.

130. Shaheen N, Ransohoff DF. Gastroesophageal reflux, barrett esophagus, and esophageal cancer: scientific review. JAMA 2002;287:1972-1981.

Received December 9, 2004. Accepted February 24, 2005.

Address requests for reprints to: Nicholas Shaheen, MD, MPH, CB\#7080, UNC-CH, Chapel Hill, North Carolina 27599-7080. e-mail: nshaheen@med.unc.edu; fax: (919) 843-2508.

Supported by a National Institutes of Health grant K23DK59311-01. 